\title{
MICROPOLLUTANTS IN STORMWATER DISCHARGE IN THE SWIST RIVER BASIN
}

\author{
FRANZ MICHAEL MERTENS, EKKEHARD CHRISTOFFELS, ANDREA FRANZISKA BRUNSCH \& JENS \\ WUNDERLICH-PFEIFFER \\ Erftverband, Bergheim, Germany
}

\begin{abstract}
A study was conducted from September 2010 to September 2012 at the outlet of a stormwater basin in the city of Meckenheim, near Bonn (Germany). For this purpose, a strategy was developed to collect samples from the stormwater basin located directly upstream from the point of discharge into the Swist river. Numerous locally applied pesticides, frequently used pharmaceuticals, industrial chemicals and flame retardants were detected. Median discharge load for selected micropollutants ranged from 4.0 to $19.9 \mu \mathrm{g} / \mathrm{s}$. The results showed that treatment may be necessary in the case of rainwater discharge from separate sewer systems to reduce the substance load in the receiving river.

Keywords: micropollutants, monitoring, retention soil filter, separate sewer system, stormwater sewer
\end{abstract}

\section{INTRODUCTION}

In contrast to combined sewer systems, separate sewer systems are used to collect and transport wastewater and rainwater in separate channels. Wastewater is carried to a wastewater treatment plant, while rainwater is infiltrated locally or discharged into the nearest river. To reduce hydraulic peaks in the receiving river, stormwater basins can be interposed in the stormwater sewer system. Due to the obligation in the German state of North RhineWestphalia to build separate sewer systems in areas under current development [1], the proportion of separate sewer systems within urban drainage systems is here increasing. For this reason, comprehensive analysis of pollutants in discharged rainwater is necessary to estimate the load in the receiving watercourse and to plan adequate measures when necessary.

Micropollutant loads in discharged rainwater from separate sewer systems have already been the subject of various studies. Birch et al. [2] and Zgheib et al. [3] detected pesticides and phthalates in rainwater. Burkhardt et al. [4] found high concentrations of biocides leached from building materials. To broaden knowledge on micropollutant loads in the collected rainwater in separate sewer systems, a project was funded by the Ministry for Climate Protection, Environment, Agriculture, Conservation and Consumer Protection of the State of North Rhine-Westphalia to study rainwater discharge of a representative separate sewer system in the Swist river basin, a sub-basin of the Erft river basin. The rainwater was analysed for micropollutants along with other substance groups significant for water management from September 2010 to September 2012.

\section{URBAN DRAINAGE SYSTEM, SURROUNDING LANDSCAPE AND RECEIVING RIVER}

The stormwater sewer under study drains the northeastern part of the city of Meckenheim, $12 \mathrm{~km}$ southwest of the city of Bonn (Table 1). The mixed residential and commercial drained area served by the stormwater sewer covers a surface of $0.74 \mathrm{~km}^{2}$. Meckenheim is located in the Swist sub-catchment, which is dominated by farmland interspersed with villages. There is no noteworthy contribution to the wastewater coming from industry. The study area, as a town section adjacent to farmland, is in its spatial structure typical for the Erft basin, so 
Table 1: Characteristics of the northeast Meckenheim separate sewer and the receiving Swist river at the point of discharge ( $\mathrm{SSO}=$ separate sewer outflow).

Catchment Area

\begin{tabular}{ll}
\hline City & Meckenheim; North Rhine-Westphalia \\
Runoff area & $0.74 \mathrm{~km}^{2}$ \\
Development & Largely residential \\
Population served & Approx. 7,900 \\
Stormwater basin & \\
Operation & Mechanical \\
Max. throttle outflow & $1,100 \mathrm{~L} / \mathrm{s}$ \\
Storage volume & $3,650 \mathrm{~m}^{3}$ \\
River & \\
Receiving water course & Swist (lowland river) \\
Mean runoff at the SSO & $158 \mathrm{~L} / \mathrm{s}$ \\
\hline
\end{tabular}

results should be transferrable. A stormwater basin is installed in the sewer just before the outlet into the Swist river to provide hydraulic relief.

\section{SAMPLING PROCEDURE AND STUDY SIZE}

A specifically adapted automatic sampling system was installed (Fig. 1) to permit sampling during stormwater events. In these cases, manual sampling was not feasible due to the low predictability of such events. At the outlet of the stormwater tank just before the discharge point into the Swist, an automatic sampling device with twelve 2.7-L bottles as well as a 200-L barrel was installed. The 200-L volume was necessary to examine for parasites, which pose a high risk of infection when present, even at low concentrations. The microbiological results will be published in a separate manuscript. An ultrasound-altimeter was installed in the stormwater tank to register the water level, which was used to estimate the discharge volume. The management of the sampling system and data recording was done using a programmable logic controller.

The beginning of a discharge event was registered by the ultrasound-altimeter, and the sampling procedure was activated. The sampling device took a number of 12-min composite samples from every event. With 12 bottles a maximum duration of sampling of 144 min per discharge event was possible. At the beginning of an event the $200 \mathrm{~L}$ barrel was filled automatically in a time span of $15 \mathrm{~min}$ for microbiological examinations.

A total of 62 stormwater discharge events of widely varying duration (see Fig. 2) occurred during the study period. Though some lasted longer than the 144-min maximum sampling time, it was not considered important to measure for a longer time interval because then the contents would have been relatively diluted. The maximum possible number of samples (755) can be calculated by multiplying the total number of events (62) by the length of sampling intervals (12 min). However, numerous discharge events were shorter than $144 \mathrm{~min}$ (see Fig. 2). The actual number of samples taken and analysed came to 379. In some cases, flow volume and concentrations of substances could not be measured.

The samples were stored under cool, dark conditions until they could be picked up for examination by the research team. Notification of time and location of a discharge event was 


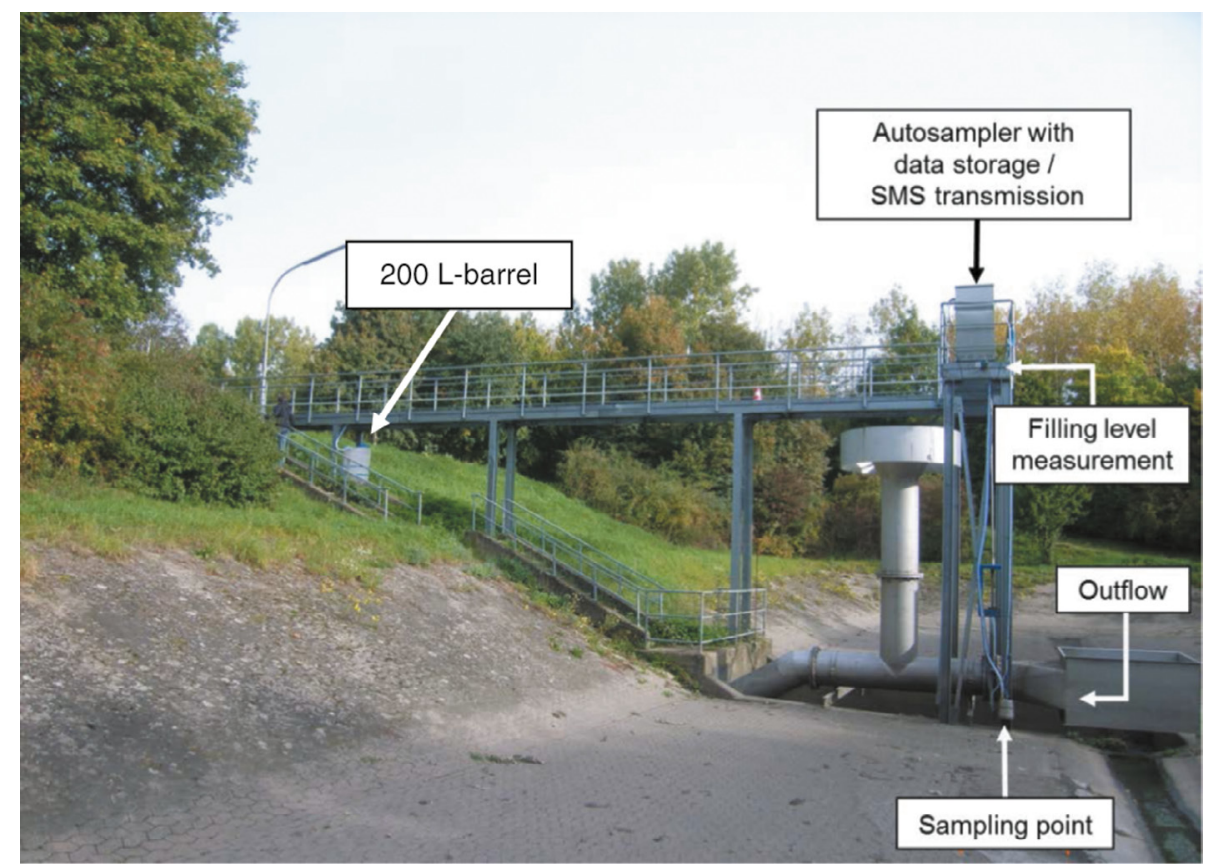

Figure 1: Sampling system in the stormwater basin of Meckenheim [5].

sent directly to the staff by SMS. Prompt pickup and processing of the samples was of particular importance as a consequence of unstable chemical compounds in the samples. From the obtained samples, 45 micropollutants were analysed throughout most of the time length of the project. Due to a laboratory expansion during the project period, the sampling strategy and the parameter set were changed. For this reason, a portion of samples was analysed as one composite sample representing a whole discharge event, but with an extended scope of parameters. Here, analysis was performed to test for the presence of 137 different micropollutants (pesticides, pharmaceuticals, flame retardants, industrial chemicals and the stimulant caffeine).

\section{VOLUME AND DURATION OF DISCHARGE EVENTS}

The data required to calculate flow volume and duration of discharge could be collected for 46 of the 62 events. Cluster analysis (SPSS $14^{\circ}$ ) was conducted to group the discharge events into five specific classes based on similarities in volume and discharge duration [6]. With this method 45 events were assigned to one of the five clusters. One event could not be assigned to any class and was thus declared as an outlier. Nonlinear regression analysis yielded representative hydrographs for each cluster.

The cumulative discharge volume corresponding to the duration of discharge for 45 analysed events as well as the regression curves representing each of the five clusters are depicted in Fig. 2. The results show that despite high variability of rainfall events, certain regularities in the behaviour of discharge were found. The similarities of the results within each cluster were based on comparable duration of discharges and similar flow volumes. 


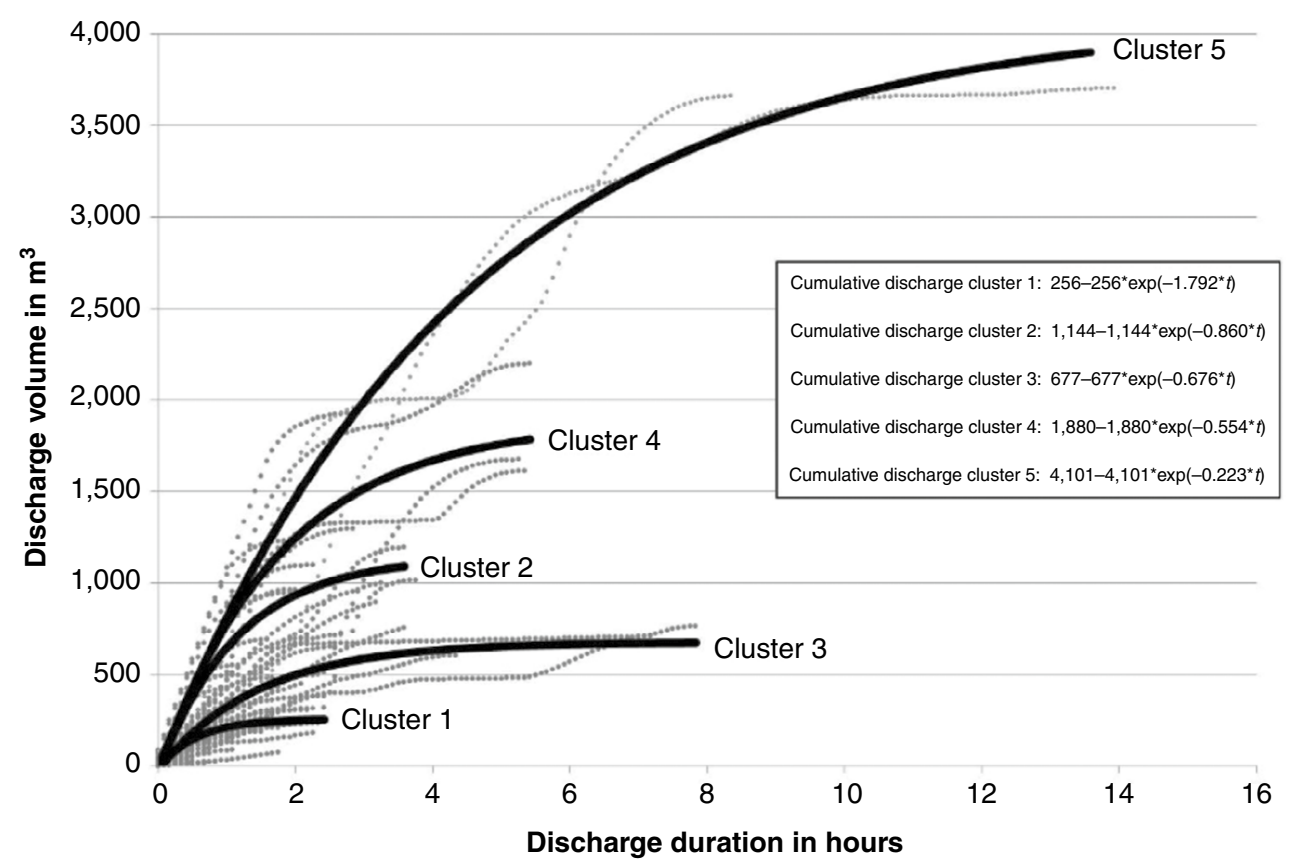

Figure 2: Five typical classes of discharge events depicted as cumulative discharge volume depending on the flow volume and duration as a result of cluster analysis ( $n=45$, dotted line), and the associated regression curves (solid line), coefficients of determination: cluster $1=0.28$; cluster $2=0.74$; cluster $3=0.66$; cluster $4=0.68$; cluster $5=0.96$.

Table 2: Characteristics of discharge types as a result of cluster analyses.

\begin{tabular}{lllr}
\hline & $\begin{array}{l}\text { Duration } \\
(\text { average hh:mm) }\end{array}$ & $\begin{array}{l}\text { Discharge volume } \\
\left(\text { average value } \mathrm{m}^{3}\right)\end{array}$ & Number \\
\hline Cluster 1 & Short $(01: 30)$ & Low $(245)$ & 22 \\
Cluster 2 & Short $(02: 30)$ & Moderate $(1,080)$ & 8 \\
Cluster 3 & Medium (04:00) & Low $(730)$ & 9 \\
Cluster 4 & Medium (04:45) & Moderate $(1,850)$ & 4 \\
Cluster 5 & Long $(11: 00)$ & High $(3,690)$ & 2 \\
\hline
\end{tabular}

The median discharge duration and discharge volume were calculated for all events within each cluster. Using median values, three groups of duration and discharge volume could be differentiated: short duration $(<3 \mathrm{~h})$, medium duration $(<3$ to $6 \mathrm{~h})$ and long duration $(>6 \mathrm{~h})$; low volume $\left(<1,000 \mathrm{~m}^{3}\right)$, moderate volume $\left(>1,000\right.$ to $\left.2,000 \mathrm{~m}^{3}\right)$ and high volume $\left(>2,000 \mathrm{~m}^{3}\right)$. The median values are listed in Table 2 . The table shows that most of the discharge events were short and the discharge volume in 31 of 45 events was low. However, there were two events in which duration was long and volume was high (cluster 5). 


\section{MICROPOLLUTANTS}

The collected samples were analysed for numerous parameters including micropollutants. In the following the frequencies of detection and concentrations of micropollutants, the calculated load and the pathways of entry will be presented and the results will be discussed against the background of the regulatory status.

\subsection{Frequencies of detection and concentrations}

Micropollutants were detected in $56 \%$ of the discharge samples from the storm sewer under study. Figure 3 shows the percentage of events in which a targeted substance was detected in at least one sample. Among pesticides, Mecoprop (37\% of all events) and MCPA (2-methyl4-chlorophenoxyacetic acid, $18 \%$ of all events) were found the most frequently. In addition, concentrations of 13 other pesticides were detected in a range from $2 \%$ to $7 \%$ of all events. The maximum concentrations of pesticides were between $0.03 \mu \mathrm{g} / \mathrm{L}$ (terbuthylazine) and $5.23 \mu \mathrm{g} / \mathrm{L}$ (MCPA).

Besides pesticides, pharmaceuticals were found in the discharge of the storm sewer (Fig. 3). In particular, the non-steroidal anti-inflammatory drugs Ibuprofen and Diclofenac

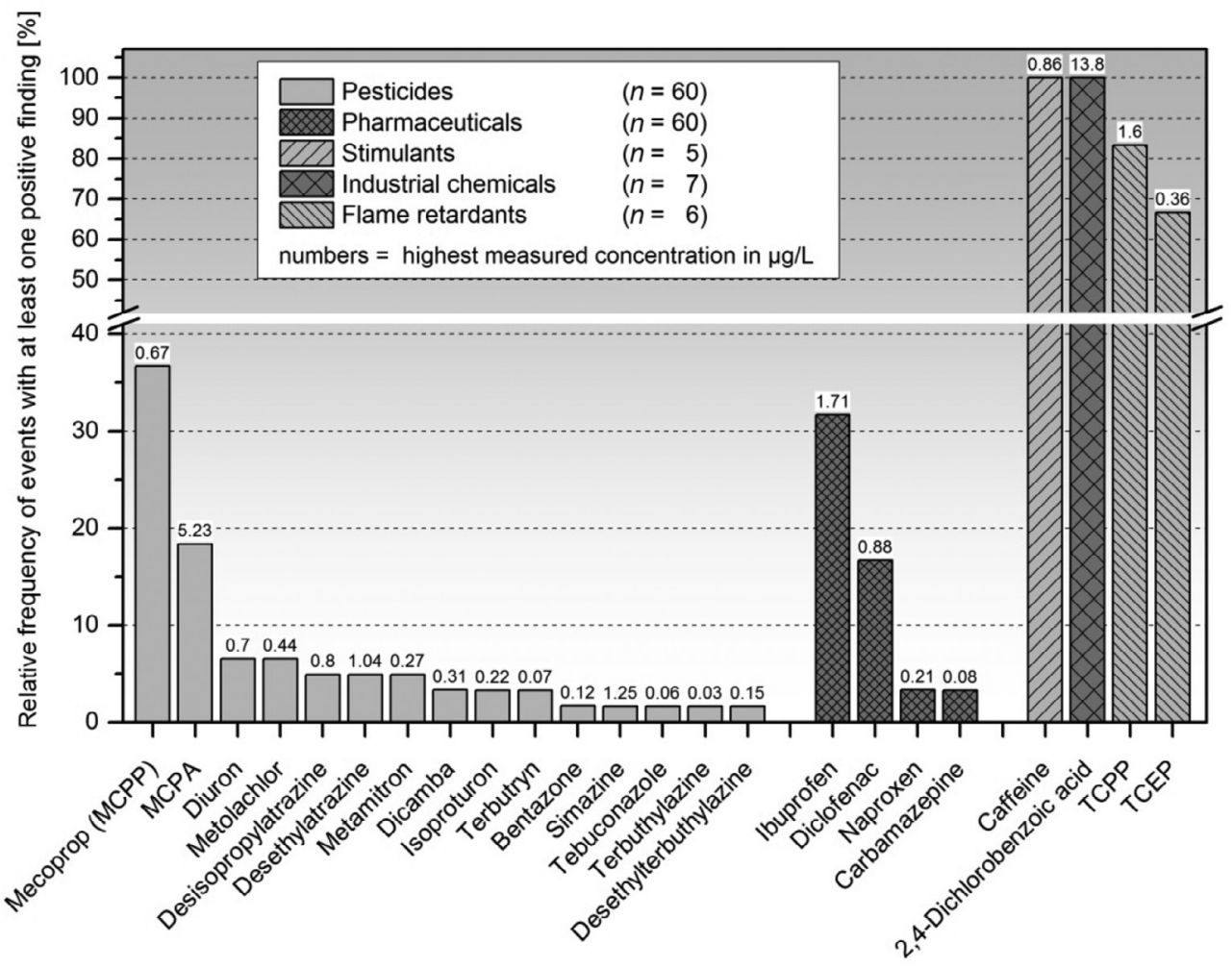

Figure 3: Micropollutants in the discharge of the Meckenheim storm sewer: relative frequency of events with at least one positive finding for each substance, listed by substance groups $(n=$ number of events in which each substance group was analysed). 
were detected in $32 \%$ and $17 \%$ of events, respectively. The maximum concentrations were between $0.08 \mu \mathrm{g} / \mathrm{L}$ (Carbamazepine) and $1.71 \mu \mathrm{g} / \mathrm{L}$ (Ibuprofen).

In the samples examined under the extended parameter set, micropollutants were found which belonged to additional substance groups including the stimulant caffeine, industrial chemicals and flame retardants (Fig. 3, far right side). The industrial chemical 2,4-dichlorobenzoic acid and the stimulant caffeine were detected in all events under study. Maximum concentrations were $13.80 \mu \mathrm{g} / \mathrm{L}$ for 2,4-dichlorobenzoic acid and $0.86 \mu \mathrm{g} / \mathrm{L}$ for caffeine. The flame retardants Tris(2-chloroisopropyl)-phosphate (TCPP) and Tris(2-chloroethyl)phosphate (TCEP) were found in $83 \%$ and $67 \%$ of all investigated events, respectively. The maximum concentrations were $1.60 \mu \mathrm{g} / \mathrm{L}$ (TCPP) and $0.36 \mu \mathrm{g} / \mathrm{L}$ (TCEP).

\section{$5.2 \mathrm{Load}$}

Besides the frequency of occurrence and concentrations of micropollutants in the storm sewer discharge, the discharged load is of particular interest for the evaluation of water contamination in the receiving river. Figure 4 shows the discharged load for selected micropollutants. The calculation was made using the average concentration of all samples of the individual events and the average volume of discharge during the sampling period. Only events that show substance concentrations above the detection limit were considered. The calculated

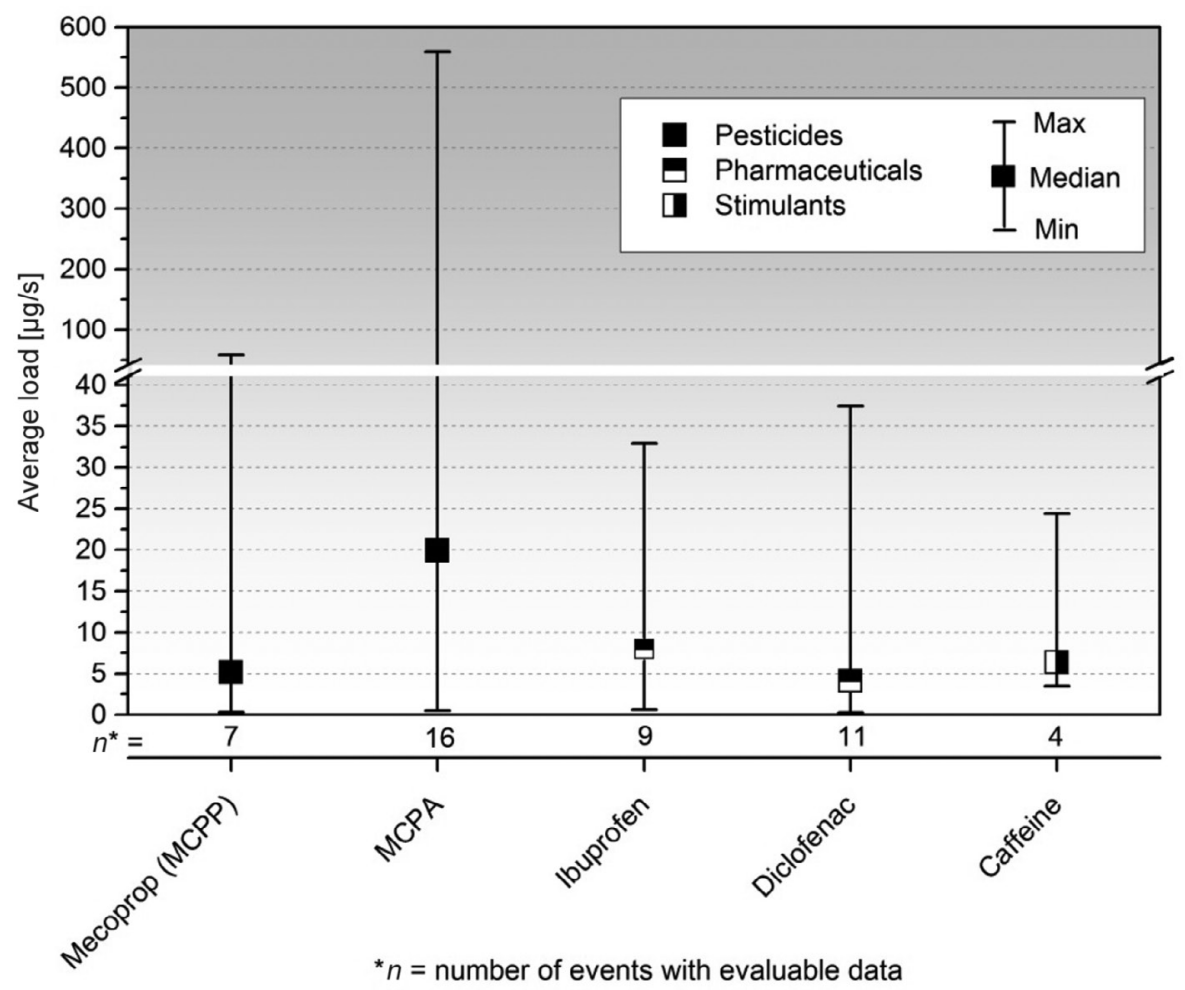

Figure 4: Loads for frequently occurring micropollutants in the storm sewer discharge of the Meckenheim separate sewer. 
Table 3: Occurrence of positive findings depended on the winter/summer half-year.

\begin{tabular}{|c|c|c|c|c|}
\hline & Pharmaceuticals & Pesticides & & \\
\hline Positive findings & Diclofenac & Ibuprofen & MCPA & MCPP \\
\hline $\begin{array}{l}\text { Positive findings[en] } \\
\text { Portion of all samples } \\
(n=379)\end{array}$ & $42[\mathrm{en}] 11 \%$ & $68[\mathrm{en}] 18 \%$ & $73[\mathrm{en}] 19 \%$ & $83[\mathrm{en}] 22 \%$ \\
\hline $\begin{array}{l}\text { Winter half-year[en] } 27 \\
\text { of } 62 \text { events }(44 \%)\end{array}$ & $35(83 \%)$ & $53(78 \%)$ & $50(68 \%)$ & $47(57 \%)$ \\
\hline $\begin{array}{l}\text { Summer half-year[en] } 35 \\
\text { of } 62 \text { events }(56 \%) \\
\text { Related to half-year }\end{array}$ & $7(17 \%)$ & $15(22 \%)$ & $23(32 \%)$ & $36(43 \%)$ \\
\hline Winter half-year & $9 \%$ & $14 \%$ & $13 \%$ & $12 \%$ \\
\hline Summer half-year & $2 \%$ & $4 \%$ & $6 \%$ & $10 \%$ \\
\hline
\end{tabular}

median loads for some of the most frequently occurring micropollutants (see Fig. 3) were between 4.0 and $19.9 \mu \mathrm{g} / \mathrm{s}$, with maximum loads above $500 \mu \mathrm{g} / \mathrm{s}$ for MCPA.

The calculated micropollutant input loads were used to estimate the load of the receiving watercourse stemming from the Meckenheim storm sewer. It should be noted that the occurrence (positive findings) of the detected pharmaceuticals and pesticides depended on the respective times of examination. Pharmaceuticals and pesticides were found more frequently during the two winter half-years (1 November-30 April) covered by the study. By contrast, industrial chemicals and the stimulant caffeine were found in the storm sewer discharge nearly continuously. Table 3 shows the pharmaceuticals and pesticides under study which were detected with more than 40 positive findings of the 379 analyses conducted during the monitoring period from September 2010 to September 2012. About 83\% of Diclofenac findings stemmed from the winter half-year, but only $17 \%$ from the summer half-year, although more separate sewer outflow events occurred during the summer halfyear $(56 \%)$ than during winter half-year (44\%). The same is true for Ibuprofen with $78 \%$ and $22 \%$, respectively. The pesticides MCPA and MCPP also show more positive findings during the winter half-year than in the summer half-year, but not as strongly as for pharmaceuticals.

The winter half-year period was selected to estimate the expected range of the discharge input load for Ibuprofen. Based on the collected data from the monitoring period, it was determined that in sum $4 \mathrm{~h}$ stormwater from the Meckenheim storm sewer was discharged into the Swist during a winter period. To generate a best-case scenario for the winter halfyear, it was assumed that all discharge events of this half-year period belong to cluster 1 (short duration, low discharge volume, see Table 2). For the worst-case scenario, it was estimated that in this period all discharge events belong to cluster 4 (medium duration, moderate discharge volume). With median concentrations representing winter half-year for Ibuprofen of $0.31 \mu \mathrm{g} / \mathrm{L}$, Ibuprofen input load for the winter half-year was calculated to be in the range from $196 \mathrm{mg}$ (best case) to $519 \mathrm{mg}$ (worst case).

\subsection{Pathways of entry}

Pathway of entry will be discussed in reference to the most frequently occurring micropollutants listed in Fig. 3. One of the most important causes of the detected pollution in stormwater 
discharge appeared to be faulty connections of wastewater piping to the stormwater sewer. The visible residues (sanitary articles) of domestic wastewater in the stormwater tank provided a clear sign of contamination by this means. Such an assumption was reinforced by the high number of positive findings of the stimulant caffeine, which is a typical indicator for domestic wastewater. Faulty connections also explain the pollution of the collected stormwater with pharmaceuticals. The two most often found pharmaceuticals were Ibuprofen and Diclofenac, which are widely available 'over the counter'. The active ingredients of the two analgesics are partly excreted after application or washed off when applied externally.

Pesticide pollution of stormwater from the separate sewer system under study likely originated either from farmyard runoff or from incorrect private use of pesticides on paved areas. The pesticides that occurred most frequently (MCPA, Mecoprop) are used in agriculture and in private homes as weed killers. The two agents are commercially available together with other substances such as Dicamba, 2,4-D, Clopyralid or Fluroxypyr as a combined preparation - marketed as 'lawn weed free' [7]. Another source of pollution with Mecoprop is bitumen roof sheeting, in which this substance is used as an agent to prevent against rooting [8]. The herbicide Diuron, which has not been authorized for agricultural use since 2007, is added to building materials to prevent growth of moss on exterior wall paints. Biocides used in building materials are washed out during rain events and thus enter the storm sewers. Burkhardt et al. [4] proved the occurrence of leaching from building materials in both laboratory and field studies. They concluded that storm sewer water from catchments with predominantly new or newly refurbished buildings is especially likely to contain biocides such as Mecoprop, Diuron and Terbutryn.

The numerous positive findings for flame retardants such as TCEP and TCPP are due to their ubiquitous distribution in the environment. These substances are also in use as additives to many everyday items as well as in building materials. Klemmlein et al. [9] have demonstrated the steady emissions of flame retardants by outgassing from everyday items. For example, a TCPP emission of up to $140 \mathrm{~g} / \mathrm{m}^{2} / \mathrm{h}$ was measured from assembly foams. Rainwater pollution is thus driven in part by wash-off from paved areas, in part by atmospheric deposition.

\subsection{Regulatory status}

Some of the frequently detected micropollutants mentioned in Section 5.3 are of regulatory concern. MCPA and Mecoprop are listed in the German Federal Surface Water Ordinance [10] as river-basin-specific pollutants with an EQS (Environmental Quality Standard) of $0.1 \mu \mathrm{g} / \mathrm{L}$ as an annual average. The biocide Diuron has also been classified in this listing as a priority substance. A maximum concentration of $1.8 \mu \mathrm{g} / \mathrm{L}$ and an annual average EQS of $0.2 \mu \mathrm{g} / \mathrm{L}$ should be respected for this substance. Although pharmaceuticals have not yet been listed in European or national regulations, the painkiller Diclofenac is placed on the watch list of substances for which monitoring data should be collected to facilitate identification of appropriate measures against risk from the substances in question [11].

\section{CONCLUSION}

This study shows that water from the rainwater channel in separate sewer systems can be significantly polluted with micropollutants. In particular, surface waters with low mean runoff could be influenced considerably by pollutant loads discharged from stormwater sewers, possibly resulting in non-compliance with legal requirements (e.g. German Federal Surface Water Ordinance [10]). For this reason, a need for action is at hand wherever a further 
build-out of urban drainage systems is undertaken. Two options exist to reduce pollution arising from stormwater discharge. The first is to eliminate faulty connections from wastewater to the storm sewer. The other is to perform advanced treatment of the collected rainwater by means of retention soil filters [12]. Retention soil filters can also be a practical solution with which the hydraulic stress in rivers brought about by stormwater can be significantly attenuated.

\section{ACKNOWLEDGEMENTS}

This study was conducted in the framework of the research and development project 'Examination and Evaluation of Measures to Reduce Physico-chemical and Hygienic-microbiological Loads in Rivers with the Example of the Swist River' funded by the Ministry for Climate Protection, Environment, Agriculture, Conservation and Consumer Protection of the federal state of North Rhine-Westphalia. The authors are grateful for the financial support of the project. Thanks also to B. Smallberg and colleagues from Erftverband and the Institute for Hygiene and Public Health.

\section{REFERENCES}

[1] MURL (Ministerium für Umwelt Raumordnung und Landwirtschaft), Niederschlagswasserbeseitigung gemäß $\$ 51$ a des Landeswassergesetzes RdErl. d. Ministeriums für Umwelt, Raumordnung und Landwirtschaft IV B 5 - 673/2-29010/IV B 6 - 031002 0901 v. 18.5.1998 (Collecting and Draining Rain Water according to § 51a Water Act of North Rhine-Westphalia, Circular of the Ministry of Environment, Planning and Agriculture IV B 5 - 673/2-29010/IV B 6 - 0310020901 v. 18.5.1998), Düsseldorf, 1998.

[2] Birch, H., Mikkelsen, P.S., Jensen, J. \& Lutzhoft, H.-C.H., Micropollutants in stormwater runoff and combined sewer overflow in the Copenhagen area, Denmark, Water Science \& Technology, 64(2), pp. 485-493, 2011. DOI: 10.2166/wst.2011.687.

[3] Zgheib, S., Moilleron, R. \& Chebbo, G., Priority pollutants in urban stormwater: Part 1 - Case of separate storm sewers, Water Research, 46(20), pp. 6683-6692, 2012. DOI: 10.1016/j.watres.2011.12.012.

[4] Burkhardt, M., Kupper, T., Hean, S., Haag, R., Schmid, P., Kohler, M. \& Boller, M., Biocides used in building materials and their leaching behavior to sewer systems, Water Science \& Technology, 56(12), pp. 63-67, 2007. DOI: 10.2166/wst.2007.807.

[5] Swist IV, Abschlussbericht, Überprüfung und Bewertung von Maßnahmen zur Reduzierung der chemisch-physikalischen und hygienisch-mikrobiologischen Belastungen von Fließgewässern am Beispiel der Swist (Review and assessment of measures to reduce the chemical-physical and hygienic-microbiological load of the river waters, using the example of Swist), Erftverband and Institut für Hygiene und Öffentliche Gesundheit der Universität Bonn im Auftrag des MKULNV NRW: Bergheim/Bonn, p. 113, 2012.

[6] Christoffels, E., Monitoring und Modellanwendung - Entwicklung eines Immissionsinventars am Beispiel der Erft,(Monitoring and Model Application - Development of an Immission Inventory with the Example of the Erft River), ISBN 978-3-00-024445-2, Erftverband: Bergheim, 2008.

[7] BVL (Bundesamt für Verbraucherschutz und Lebensmittelsicherheit), Pflanzenschutzmittelverzeichnis (Register of plant protection), available at http://www.bvl.bund.de/ DE/04_Pflanzenschutzmittel/01_Aufgaben/02_ZulassungPSM/01_ZugelPSM/psm_ ZugelPSM_node.html (accessed 16 April 2015). 
[8] Wittner, I., Dynamik von Biozid- und Pestizideinträgen (Dynamics of biocide and pesticide input), Eawag News, 67d(Juni), pp. 8-11, 2009.

[9] Kemmlein, S., Hahn, O. \& Jann, O., Emissionen von Flammschutzmitteln aus Bauprodukten und Konsumgütern (Emissions of flame retardants from building material and consumer products), Umweltforschungsplan des Bundesumweltministeriums für Umwelt, Naturschutz und Reaktorsicherheit, Forschungsbericht 29965, 2003.

[10] OGewV, Oberflächengewässerverordnung vom 18. März 2016 (BGBl. I S. 1429), (German Federal Surface Water Ordinance), 2016.

[11] European Commission, Proposal for a Directive of the European Parliament and of the Council amending Directives 2000/60/EC and 2088/105/EC as regards priority substances in the field of water policy, COM (2011) 876 final 2011/0429 (COD), available at http://eurlex.europa.eu/LexUriServ/site/de/com/2011/com2011_0876de01.pdf (acessed 12 April 2014).

[12] Mertens, F. M., Christoffels, E., Schreiber, C. \& Kistemann, T., Rückhalt von Arzneimitteln und Mikroorganismen am Beispiel des Retentionsbodenfilters Altendorf (Retention of pharmaceuticals and microorganisms using the example of the retention soil filter Altendorf), Korrespondenz Abwasser Abfall, 59(12), pp. 1137-1143, 2012. DOI: 10.3243/kwe2017.03.002. 